\title{
MODELAGEM FÍSICA E COMPUTACIONAL DE ONDAS GERADAS PELO VENTO EM UM TERMINAL PORTUÁRIO: O DESEMPENHO DO MODELO SWAN 40.51 EM UMA REGIÃO COM ELEVADA REFLEXÃO E DIFRAÇÃO
}

\author{
Rafael B. Paes-Leme ${ }^{1}$, Nelson Violante-Carvalho² Domenico Accetta $^{3}$ e Saulo Meirelles ${ }^{4}$ \\ Recebido em 10 outubro, 2007 / Aceito em 3 março, 2008
}

Received on October 10, 2007 / Accepted on March 3, 2008

\begin{abstract}
The SWAN wave model is widely used in coastal waters, and the main focus of this work is on its application in a harbour. A recently released version of SWAN now includes an approximation to compute diffraction, however there are few published works that discuss this matter. The performance of the model is therefore investigated in a harbour where reflection and diffraction play a relevant role. To assess its estimates, a phase-resolving Boussinesq wave model is employed as well, together with measurements carried on at a small-scale model of the area behind the breakwater. For irregular, short-crested waves with broad directional spreading, the importance of diffraction is relatively small. On the other hand, reflection of the incident waves is significant, increasing the energy inside the harbour. Nevertheless, when the SWAN model is set to compute diffraction and reflection simultaneously, it does not achieve convergence. It is concluded that for situations typically encountered in harbours, with irregular waves near reflective obstacles, the model should be used without diffraction.
\end{abstract}

Keywords: wind waves, SWAN 40.51 wave model, wave reflection and diffraction.

RESUMO. 0 modelo de geração e propagação de ondas SWAN é amplamente utilizado pela comunidade científica para obtenção de estimativas do espectro de ondas em áreas costeiras, lagos e estuários. 0 cálculo da difração não era representado no modelo tornando as simulações em regiões próximas a obstáculos ou portos menos precisas. Recentemente, uma aproximação para o cálculo da difração foi implementada, porém poucos trabalhos publicados até o momento abordam esta questão. Seu desempenho é então investigado em um terminal portuário, uma região onde difração e reflexão são importantes. Para validar suas estimativas, um modelo baseado nas equações de Boussinesq é empregado juntamente com medições realizadas em um modelo em escala reduzida do porto. Para ondas irregulares, com espalhamento direcional mais amplo, a importância da difração é comparativamente menor. A reflexão das ondas incidentes, por sua vez, é significativa aumentando a energia dentro do porto. Contudo, os cálculos do modelo não convergem quando SWAN é configurado para computar difração e reflexão simultaneamente. Conclui-se que, para situações tipicamente encontradas em portos, com ondas irregulares próximas a obstáculos refletivos, a presente versão do SWAN deve ser configurada sem a opção de cálculo da difração.

Palavras-chave: ondas geradas pelo vento, modelo de ondas SWAN 40.51, reflexão e difração de ondas.

\footnotetext{
${ }^{1}$ Faculdade de Oceanografia, Universidade do Estado do Rio de Janeiro, UERJ. Rua São Francisco Xavier, 524, 20550-013, Rio de Janeiro, RJ, Brasil. Tel.: +55 (21) 2587-7976 - E-mail: rafaelpaesleme@ig.com.br

${ }^{2}$ Faculdade de Oceanografia, Universidade do Estado do Rio de Janeiro, UERJ. Rua São Francisco Xavier, 524, 20550-013, Rio de Janeiro, RJ, Brasil. Tel.: +55 (21) 2587-7976 - E-mail: violante_carvalho@yahoo.co.uk

3 Instituto de Pesquisas Hidroviárias, INPH, Rua General Gurjão 166, Caju, Rio de Janeiro, Brasil. E-mail: domenico@inph.com.br

${ }^{4}$ Faculdade de Oceanografia, Universidade do Estado do Rio de Janeiro, UERJ. Rua São Francisco Xavier, 524, 20550-013, Rio de Janeiro, RJ, Brasil. Tel.: +55 (21) 2587-7976 -E-mail: s_meirelles@click21.com.br
} 


\section{INTRODUÇÃo}

0 conhecimento do clima de ondas em uma região é fundamental para a implantação de qualquer obra costeira como portos, piers e quebra-mares. Parte considerável da energia transferida da atmosfera para o oceano é transportada na forma de ondas, sendo liberada muito rapidamente influenciando de forma direta a hidrodinâmica local, o transporte de sedimentos e a morfologia da costa.

Para a implantação de qualquer obra nesta região se torna necessário determinar as principais características das ondas como altura significativa, período e direção de propagação por intervalos de tempo suficientemente longos para a caracterização de sua variabilidade espacial e temporal. Para tanto são empregadas técnicas de medição, com sensores operando remotamente (dados de altimetria ou de radar de abertura sintética SAR), ou 'in situ' como bóias e PUV gauges, entre outros (ver, por exemplo, Tucker \& Pitt (2001)). Adicionalmente podem ser empregados, com 0 intuito de incrementar o conhecimento da hidrodinâmica local, modelos numéricos que simulam no computador a propagação das ondas, ou ainda, a construção de modelos físicos reduzidos onde uma determinada região, como um porto, é representada em escala no laboratório. 0 emprego de modelos tanto numéricos quanto físicos visa, principalmente, otimizar o projeto das estruturas, com segurança e economia.

A modelagem física reduzida é o conjunto de atividades que caracterizam a utilização de técnicas de representação de estruturas em modelos, em escala reduzida, para conhecimento do comportamento de tais estruturas quando submetidas aos fenômenos hidráulicos. Tem por finalidade a investigação de problemas ambientais, representando possíveis situações que não são previstas analiticamente.

Com 0 avanço da informática, os modelos numéricos têm sido amplamente aperfeiçoados e utilizados, porém, para que os problemas sejam solucionados de maneira eficaz, é importante que os dados sejam fornecidos ao modelo com riqueza de detaIhes. A opção mais eficaz em uma obra seria realizar um estudo numérico e um físico, simultaneamente, em conjunto com medições de ondas realizadas nas proximidades.

As ondas geradas pelo vento representam o principal fator no movimento de navios atracados, causando também maiores esforços nas amarras, defensas e estruturas do cais. 0 distúrbio dentro das bacias portuárias é um dos fatores mais importantes para selecionar os locais de construção e determinar a sua melhor configuração. A propagação de ondas dentro de um porto protegido por quebra-mares é um processo complexo que envolve empinamento, refração, difração e reflexão (ver Meirelles \& Violante-Carvalho (2007) para uma revisão dos principais fenômenos que ocorrem em água rasa). Neste trabalho é apresentado um estudo sobre a propagação de ondas irregulares dentro do Terminal Portuário da Companhia Siderúrgica de Tubarão (CST) em Vitória - ES através da modelagem física reduzida e da modelagem computacional empregando dois modelos numéricos diferentes, ambos bastante utilizados pela comunidade científica. A principal motivação deste estudo é avaliar a mais nova versão do modelo de terceira geração SWAN 40.51, que apresenta como mais importante melhoramento em relação às versões anteriores a inclusão do cálculo da difração. Porém, um número pequeno de trabalhos científicos aborda o efeito da difração no SWAN, como por exemplo o trabalho de Enet et al. (2006). Buscando contribuir para a compreensão do efeito da difração estimado pelo SWAN em uma região portuária, seu desempenho é comparado com um modelo físico e com o modelo numérico MIKE 21 BW.

\section{ÁREA DE ESTUDO}

A área de estudo compreende as redondezas do Terminal Portuário da Companhia Siderúrgica de Tubarão (CST), em Vitória ES (Fig. 1), entre as latitudes 20¹4'S e 20¹9'S e entre as Iongitudes $40^{\circ} 12^{\prime} \mathrm{W}$ e $40^{\circ} 15^{\prime} \mathrm{W}$. Vitória, de uma forma geral, está sujeita a ondas de maior energia provenientes de quadrante Sul, associadas à passagem de sistemas frontais (INPH, 2003a).

Durante o período de 28 de maio a 11 de dezembro de 2001, totalizando 198 dias, o Instituto de Pesquisas Hidroviárias (INPH) realizou uma campanha de medições de ondas ao largo do Porto de Tubarão (localizado nas proximidades do Terminal Portuário da CST), empregando um ondógrafo direcional do tipo Waverider. 0 ondógrafo é munido de acelerômetros, onde a partir das medições de aceleração é possível computar os deslocamentos da superfície do mar. 0 instrumento foi instalado no ponto de coordenadas geográficas 20¹7'18"S e 40¹2'54"W, em uma profundidade de aproximadamente $21 \mathrm{~m}$. Para a análise dos dados da bóia foram empregadas técnicas clássicas de Fourier, como as apresentadas em Violante-Carvalho et al. (2004).

As medições não abrangem um ano completo, que é 0 intervalo mínimo requerido para a caracterização da variabilidade sazonal em uma região. Porém foram realizadas durante o período que é considerado pelos administradores do Porto de Tubarão como sendo o mais crítico, devido à maior ocorrência de passagem de frentes frias pelo local com a geração das maiores alturas de onda (INPH, 2003b).

A partir dos dados fornecidos pelo ondógrafo, foram selecio- 


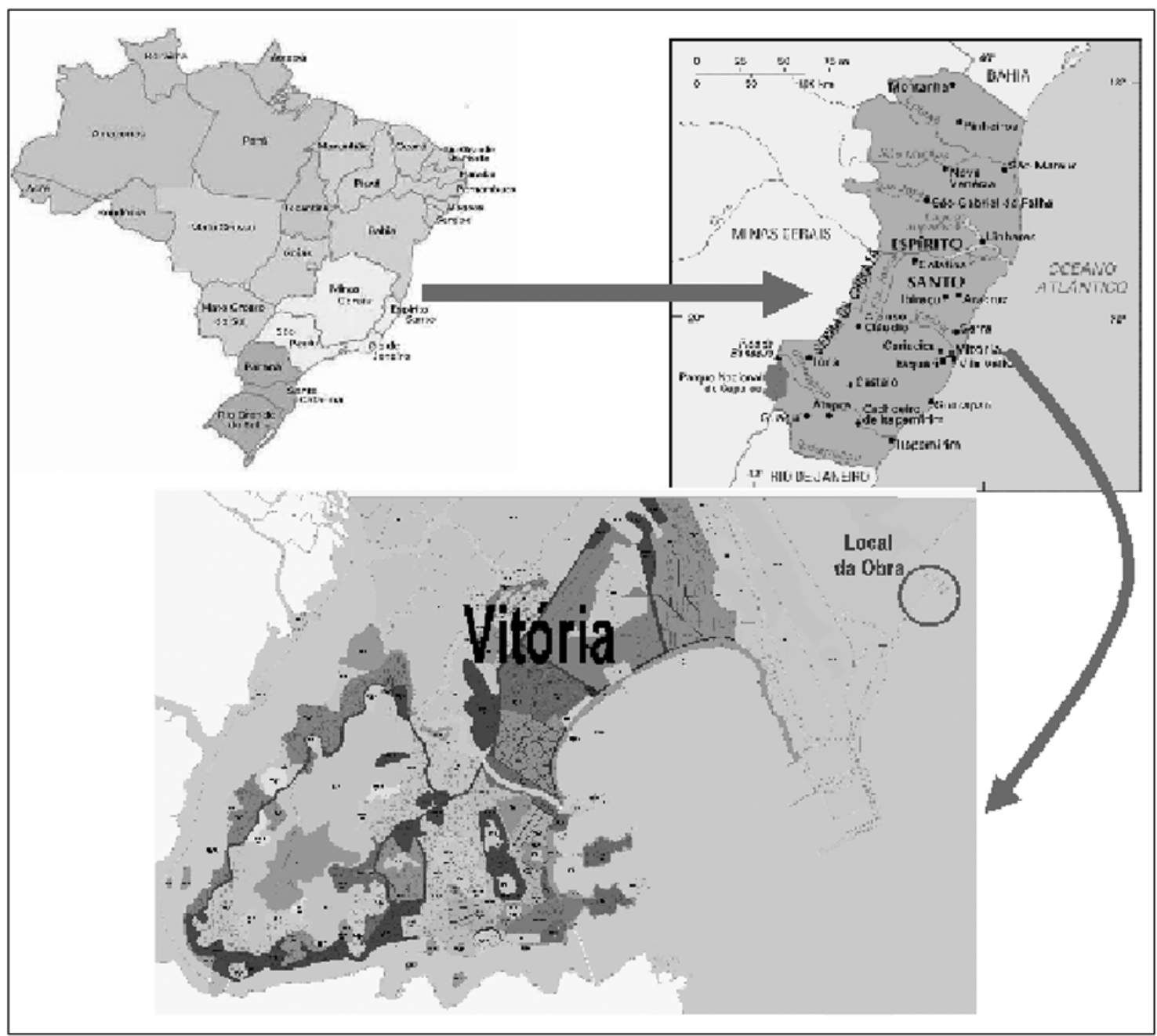

Figura 1 - Localização da área de estudo, no litoral do Município de Vitória, Estado do Espírito Santo, região sudeste do Brasil.

nadas as medições de maior energia (INPH, 2003b). Os cinco registros correspondentes às maiores alturas significativas foram os que apresentavam direções médias de propagação de $120^{\circ}$, $135^{\circ}, 150^{\circ}, 165^{\circ}$ e $180^{\circ}$. Os dados obtidos com 0 ondógrafo foram então empregados para analisar, utilizando os modelos numéricos e o modelo reduzido, as situações mais desfavoráveis para a operação do porto.

\section{MODELOS NUMÉRICOS}

\section{SWAN}

SWAN é um modelo numérico de terceira geração desenvolvido para estimar as condições das ondas em pequena escala, como em regiões costeiras, lagoas, estuários e, ainda, tanques (Booij et al., 1999), sendo capaz de representar todos os processos rele- vantes de geração, dissipação e propagação. As ondas são computadas através da evolução do espectro de densidade de ação no plano bidimensional, representada pela Equação do Balanço da Ação Espectral:

$$
\begin{aligned}
\frac{\partial}{\partial t} N & +\frac{\partial}{\partial x} c_{x} N+\frac{\partial}{\partial y} c_{y} N+\frac{\partial}{\partial \sigma} c_{\sigma} N \\
+ & \frac{\partial}{\partial \theta} c_{\theta} N=\frac{\partial S}{\partial \sigma} .
\end{aligned}
$$

0 primeiro termo do lado esquerdo de (1) representa a taxa de variação da densidade de ação no tempo. 0 segundo e 0 terceiro termo indicam a propagação da densidade de ação no espaço geográfico (com velocidades de propagação $c_{x}$ e $c_{y}$ no plano $x, y$, respectivamente). 0 quarto termo trata da variação das freqüências relativas devido à mudanças de profundidade $\mathrm{e}$ devido à presença de correntes (com velocidade de propagação 
$\left.c_{\sigma}\right)$. 0 quinto termo, por sua vez, representa a refração induzida pelas variações de profundidade e de corrente (com velocidade de propagação $\left.c_{\theta}\right)$. 0 termo fonte $S(=S(\sigma, \theta)$ ) representa os efeitos de geração, dissipação e interações não-lineares onda-onda.

A integração de (1) é implementada no SWAN com um esquema de diferenças finitas em cinco dimensões: tempo, espaço geográfico (direções $x$ e $y$ ) e espaço espectral (freqüência e direção). Modelos espectrais como o WAM (WAMDI Group, 1988) e o WAVEWATCH III (Tolman, 1991) consideram de forma geral problemas não-estacionários em escalas oceânicas, enquanto que no SWAN geralmente a propagação é computada da região de água profunda até próximo à zona de arrebentação. Como o tempo de permanência das ondas nesta região é pequeno comparado com as variações temporais associadas ao vento, à maré e às correntes, é admissível que (1) seja resolvida de forma independente do tempo (steady-state solution), a forma empregada no presente trabalho.

A solução em modo estacionário, ou seja, com a eliminação do primeiro termo do lado esquerdo de (1), é alcançada através de uma série de iteraç̧ões. Cada passo de propagação para cada ponto de grid é computado dividindo o espaço direcional em 4 quadrantes. A propagação dessas componentes é denominada sweep (variando, naturalmente, de 1 a 4), onde rotacionando cada quadrante de $90^{\circ}$ se torna possível determinar a propagação da energia em todas as direções.

Porém, efeitos que possam alterar a direção de propagação das componentes de onda, como refração induzida pela batimetria ou por correntes ou ainda a difração, podem transferir energia de um quadrante para outro. Esse efeito é considerado no SWAN através de iterações sucessivas, onde em cada uma delas os 4 sweeps são computados. Para finalizar as iterações são empregados critérios para assegurar a convergência nos resultados (Zijlema \& van der Westhuysen, 2005). A computação é terminada indicando convergência quando entre iterações sucessivas 0 valor da altura significativa varia menos que $2 \%$ em pelo menos $98 \%$ dos pontos de grid cobertos por água. Enquanto esse valor não é atingido, o modelo continua repetindo suas iterações até que um número máximo, previamente estipulado, seja alcançado podendo ocorrer ou não a convergência nos resultados.

Resultados consistentes podem ser obtidos para ondas se propagando em torno de obstáculos (Booij et al., 1999), uma vez que 0 modelo computa a refração linear induzida por variações da profundidade e pela presença de correntes. A difração, por outro lado, começou a ser recentemente calculada a partir da versão 40.41. Devido ao pequeno número de trabalhos publicados, 0 desempenho do modelo em situações onde 0 efeito da difração é significativo ainda não é satisfatoriamente conhecido.

Booij et al. (1999) salientam que os efeitos da difração de ondas superficiais são convencionalmente computados pelos modelos que resolvem a fase (phase resolving mode/s), como 0 MIKE 21 BW, os quais são empregados em geral para contemplar a propagação de ondas próximo à obstáculos. Modelos espectrais (phase averaging mode/s), como o SWAN, normalmente não incluem a difração pelo fato da equação básica para representá-la não se adequar às equações governantes desses modelos.

A abordagem utilizada para incorporar o fenômeno da difração no SWAN é apresentada em Holthuijsen et al. (2003). A aproximação é baseada na Equação do Declive Suave (EDS) para refração-difração, omitindo, entretanto, as informações sobre a fase da onda. A implementação da aproximação da refraçãodifração com fase desacoplada (phase-decoupled refraction-diffraction) no SWAN, mostra que a difração de ondas aleatórias de cristas curtas baseadas na EDS pode ser combinada com os processos de empinamento, refração, geração, dissipação e interação onda-onda, geralmente computados nos modelos espectrais.

\section{MIKE 21 BW}

0 MIKE 21 BW é baseado na solução numérica de uma nova fórmula das equações de Boussinesq 2D, derivadas por Madsen et al. (1991) e Madsen \& Sorensen (1992). A maior restrição das equações de Boussinesq clássicas é sua limitação em calcular a propagação de ondas em água profunda. Porém, esta nova formulação incorpora um significante aperfeiçoamento das características de dispersão, tornando o modelo apropriado para simulação de propagação de trens de ondas que se encaminham de água profunda para água rasa.

0 modelo é capaz de reproduzir os efeitos combinados da maioria dos fenômenos de importância em água rasa, como empinamento, refração, difração e reflexão parcial de ondas irregulares de amplitude finita se propagando sobre batimetrias complexas (DHI, 1998). Pode ser aplicado na investigação da hidrodinâmica induzida pelas ondas em zonas costeiras e em portos além de propagação de trens regulares e irregulares e ressonância em portos entre outros (Hansen et al., 2005).

A versão aqui empregada não inclui aproximações realísticas para o mecanismo de quebra de ondas. Como conseqüência, este módulo não deve ser empregado onde a quebra de ondas seja importante, o que não é 0 caso da presente investigação. Hansen et al. (2005) e Sorensen et al. (2004) relatam que já existem modelos que se baseiam nas equações de Boussinesq que incluem a quebra de onda em seus cálculos. Maiores detalhes sobre 


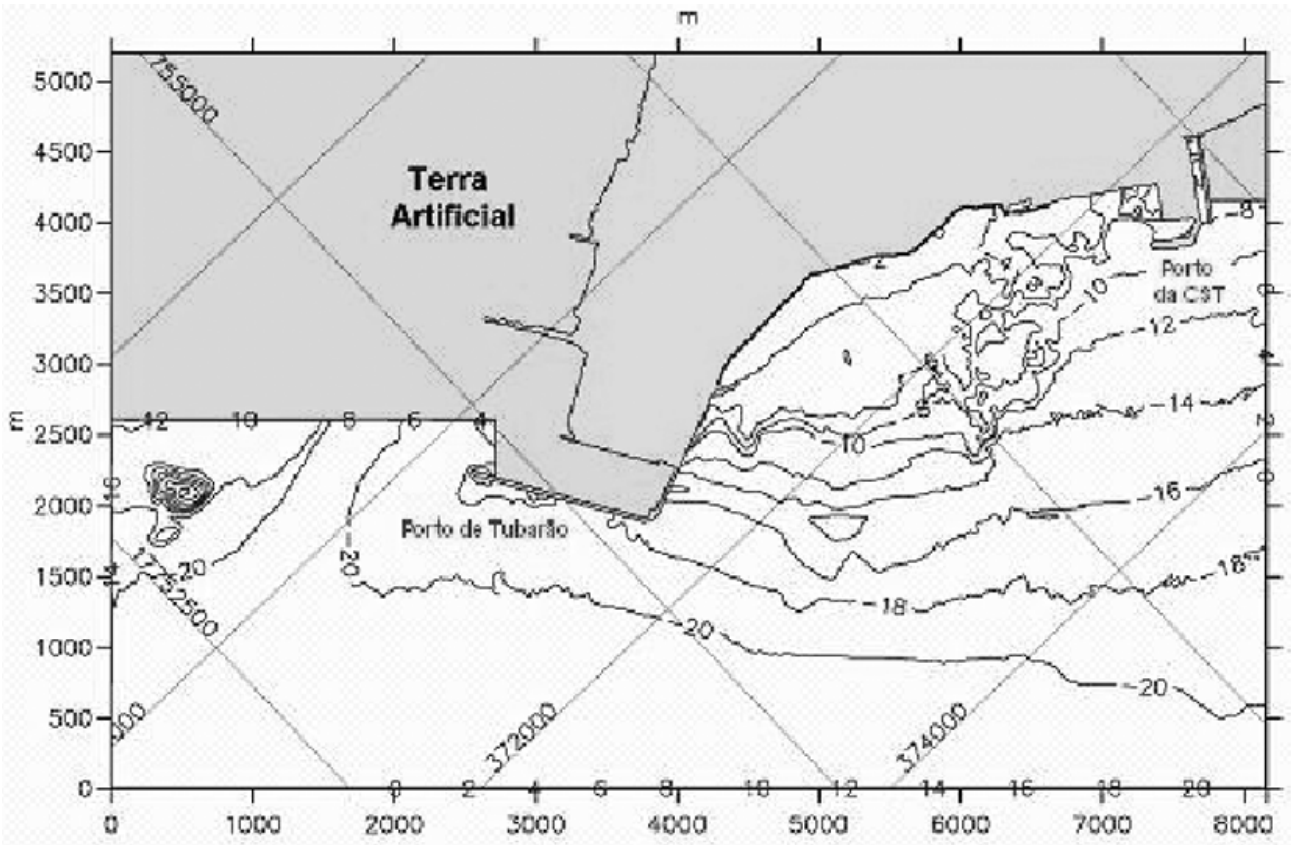

Figura 2 - Batimetria das proximidades do Porto da Companhia Siderúrgica de Tubarão. 0 porto da CST está localizado no canto superior direito da figura, enquanto que o Porto de Tubarão está localizado na porção central.

as características e as aproximações empregadas no modelo são obtidas no seu manual de operação (DHI, 1998).

\section{METODOLOGIA}

A batimetria empregada nos modelos (Fig. 2) foi obtida dos levantamentos realizados em 1999 pelo INPH na Baía do Espírito Santo e em 2002 pela Argos Serviços Hidrográficos Ltda., na área do projeto (INPH, 2003b). Nos locais mais afastados do porto, onde não foi feito levantamento batimétrico, as informações foram extraídas da Carta Náutica DHN 1410. A área descrita como 'Terra Artificial' na Figura 2 é uma região coberta por água, porém, não considerada durante as simulações. Este recurso tem como objetivo diminuir o esforço computacional, já que ela está afastada do porto não interferindo na área de interesse.

Simulações realizadas com o MIKE 21 BW indicaram que as ondas se propagando ao largo com direção de $150^{\circ}$ são as mais desfavoráveis para a operação do terminal, ou seja, a situação em que são observados os maiores valores de altura significativa dentro do porto (INPH, 2003b). Portanto esta foi a direção escoIhida para ser representada no modelo físico. Dentre as medições realizadas pela bóia, foram selecionados 4 registros diferentes com direção média de propagação em torno de $150^{\circ}$ e altura significativa de aproximadamente $1,0 \mathrm{~m}, 1,5 \mathrm{~m}, 2,0 \mathrm{~m}$ e 2,5 m. Os espectros de energia dos registros selecionados são apresenta- dos na Figura 3, enquanto que seus valores de período, direção de propagação e altura significativa estão listados na Tabela 1.

Tabela 1 - Medições obtidas pelo Waverider empregadas como entrada para 0 modelo físico. Registros de 1 a 4 correspondem, respectivamente, às Figuras 3a, 3b, 3c e 3d. Estão listados os valores do período de pico (Per Pico), período médio (Per Med), altura significativa (Alt Sig) e direção média de propagação (Dir Med) de onde as ondas estão vindo, referenciadas ao norte verdadeiro.

\begin{tabular}{|c|c|c|c|c|}
\hline Registro & Per Pico & Per Med & Alt Sig & Dir Med \\
\hline 1 & $9.1 \mathrm{~s}$ & $6.1 \mathrm{~s}$ & $0.99 \mathrm{~m}$ & $145.5^{\circ}$ \\
\hline 2 & $7.7 \mathrm{~s}$ & $5.9 \mathrm{~s}$ & $1.49 \mathrm{~m}$ & $149.7^{\circ}$ \\
\hline 3 & $8.3 \mathrm{~s}$ & $5.8 \mathrm{~s}$ & $2.00 \mathrm{~m}$ & $154.6^{\circ}$ \\
\hline 4 & $10.5 \mathrm{~s}$ & $6.4 \mathrm{~s}$ & $2.51 \mathrm{~m}$ & $144.2^{\circ}$ \\
\hline
\end{tabular}

\section{Modelos utilizados}

0 estudo em modelo reduzido de fundo fixo do terminal portuário da CST utiliza ondas irregulares reproduzidas diretamente dos registros obtidos do ondógrafo instalado ao largo do Porto de Tubarão. Foi implementado nas dependências do INPH, em escala linear de 1:50, em área própria para construção de modelos físicos reduzidos e que possui em anexo uma cabine controladora.

0 processo de trabalho no modelo reduzido compreende as etapas de geração, aquisiç̧ão e análise dos dados. Os espectros apresentados na Figura 3, obtidos com o ondógrafo, servem como dados de entrada para a geração de ondas. Na cabine de 


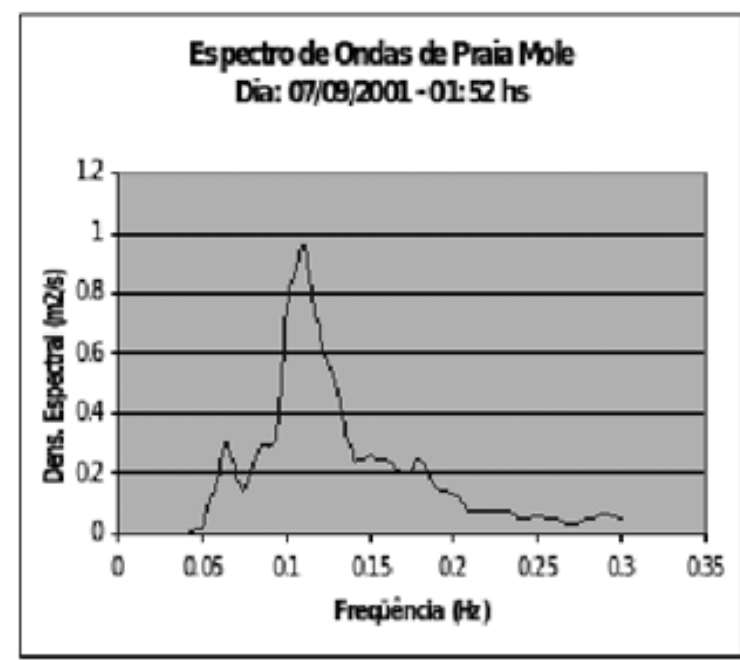

(a)

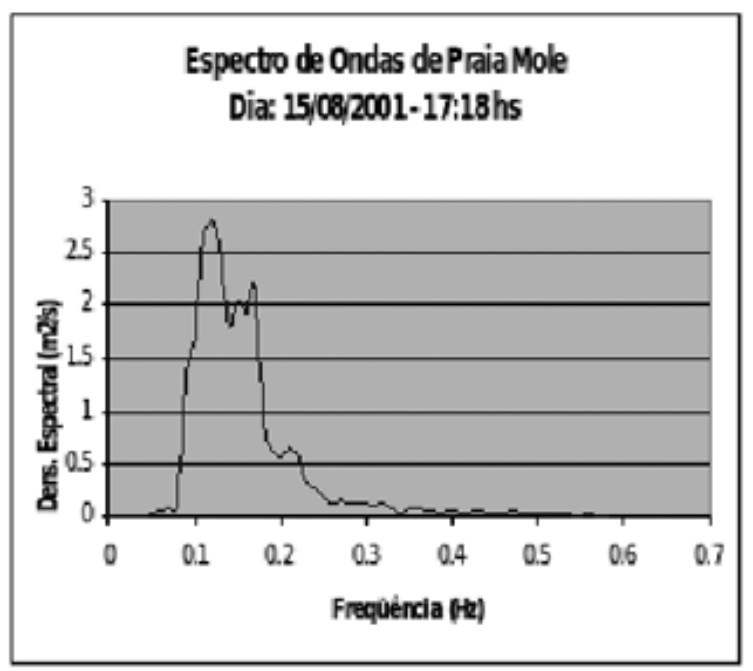

(c)

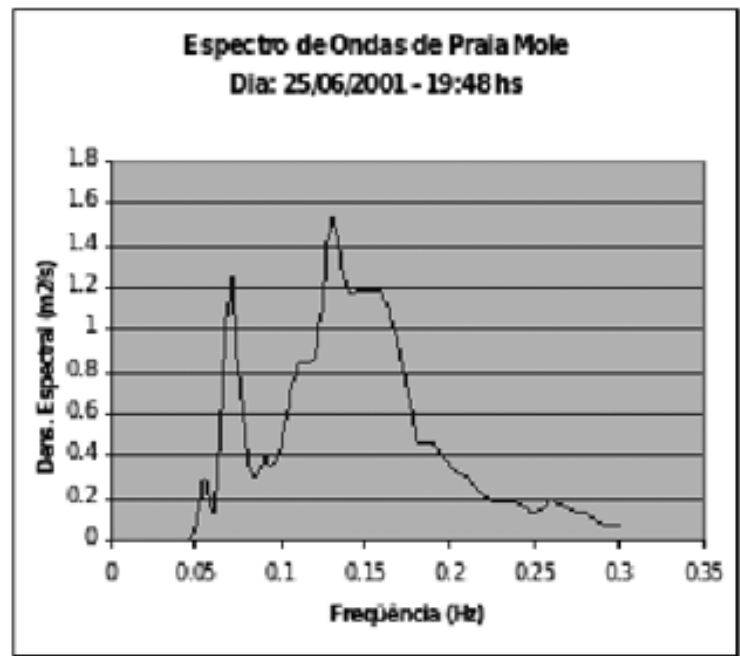

(b)
Espectro de Ondas de Praia Mole Dia: 18/82001 - 10:18 hs

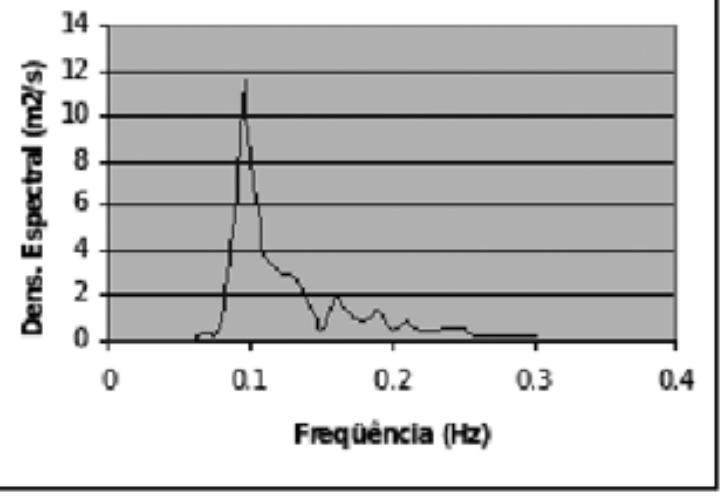

(d)

Figura 3 - Espectro de energia dos registros obtidos com o Waverider selecionados para serem utilizados nas simulações realizadas no modelo físico. Os valores de período, altura significativa e direção média de propagação estão listados na Tabela 1.

controle, dois computadores ligados em rede são utilizados na geração e aquisição dos dados e no seu processamento.

0 computador de geração emite sinais discretizados para um controlador que está no batedor de ondas, transformando esses sinais em pulsos para 0 motor. 0 batedor possui duas pás, que se movimentam conjuntamente, gerando ondas irregulares acompanhando exatamente o registro de entrada.

A medição das alturas das ondas é feita através de um conjunto de sondas resistivas, que funcionam com base no princípio da condutividade de dois eletrodos, produzindo uma voltagem de saída que é proporcional ao tamanho da parte submersa da haste
(INPH, 2003a). A variação de resistência é transferida para um aparelho condicionador de sinais convertendo-a em altura, além de corrigir este valor para a altura que a onda teria em escala real, na natureza. Em seguida, os valores são enviados para o computador de aquisição e análise.

Foram empregadas 8 sondas resistivas (sondas numeradas de 4 a 11 na Fig. 4), dispostas dentro da área que corresponde ao porto (INPH, 2003b). Os dados de altura de onda do modelo físico foram utilizados na comparação com os resultados dos modelos numéricos. As comparações foram feitas em relação aos 8 pontos dispostos sobre duas linhas, onde a linha 1 corresponde 


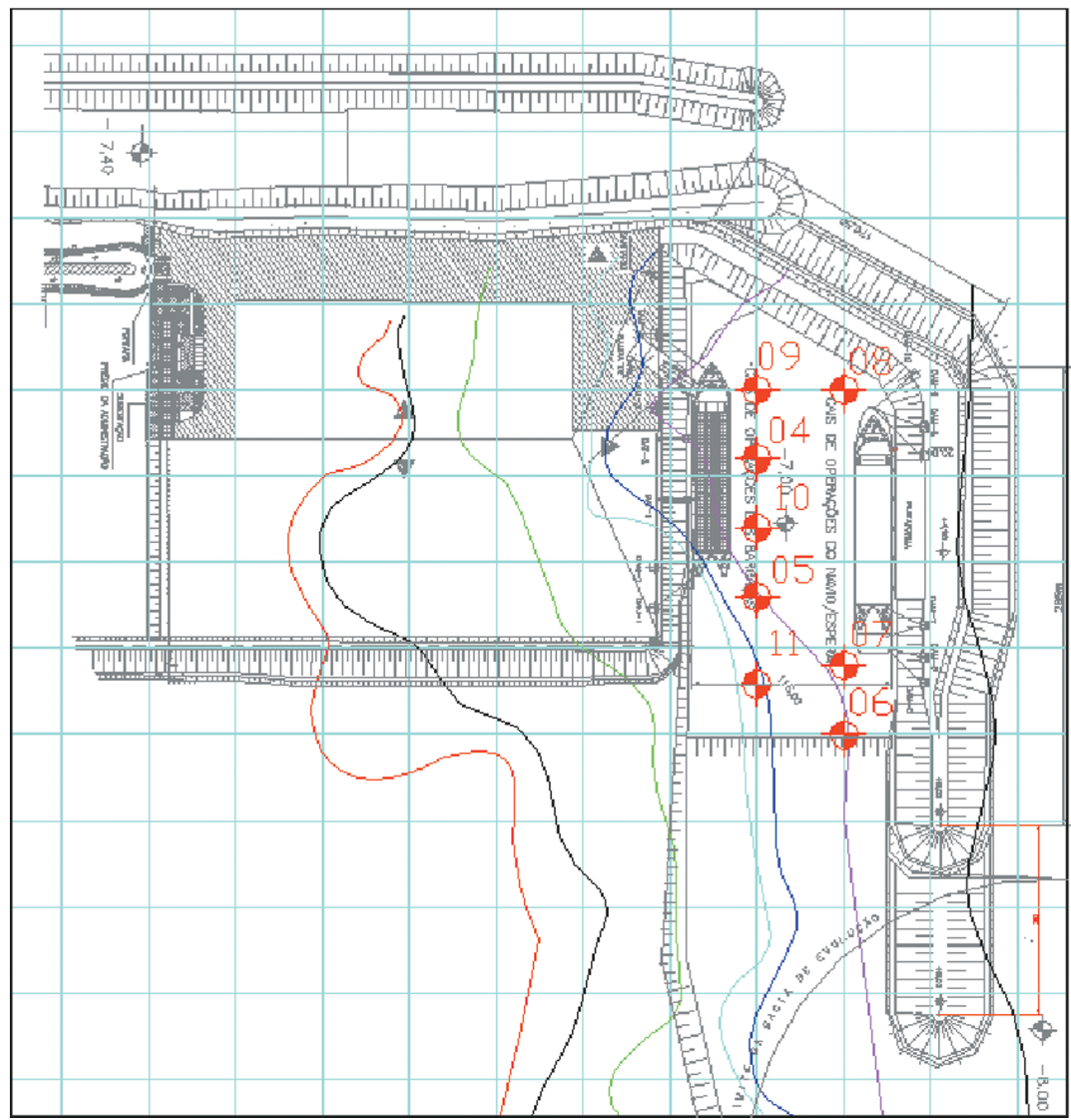

Figura 4 - Detalhe da obra do modelo reduzido do terminal portuário da CST e da localização das sondas de medição, representadas pelos números de 4 a 11.

às sondas de número 11, 5, 10, 4 e 9 e a linha 2 às sondas de número 6, 7 e 8 (Fig. 4).

As simulações empregando os modelos numéricos foram realizadas para a área compreendida na Figura 2, onde cada um dos 4 espectros com direção média de propagação de $150^{\circ}$ (Fig. 3) foi utilizado como entrada para ambos os modelos. Para efeito de comparação de resultados, são considerados somente os pontos de grid que correspondem à região do porto onde estão localizadas as sondas resistivas.
0 coeficiente de reflexão utilizado nos modelos foi de $40 \%$, que é o valor médio considerado em estruturas de enrocamento (DHI, 1998). Nas simulações empregando os dois modelos, os efeitos de vento, correntes, encapelamento, quebra de onda e interações triplas e quádruplas não foram considerados. Os modelos foram executados no modo estacionário, usando uma grade cartesiana retangular.

0 MIKE 21 BW rodou com espaçamento de grid de $8 \mathrm{~m}$, perfazendo um total de 651 por 1021 pontos. 0 modelo calcula a 


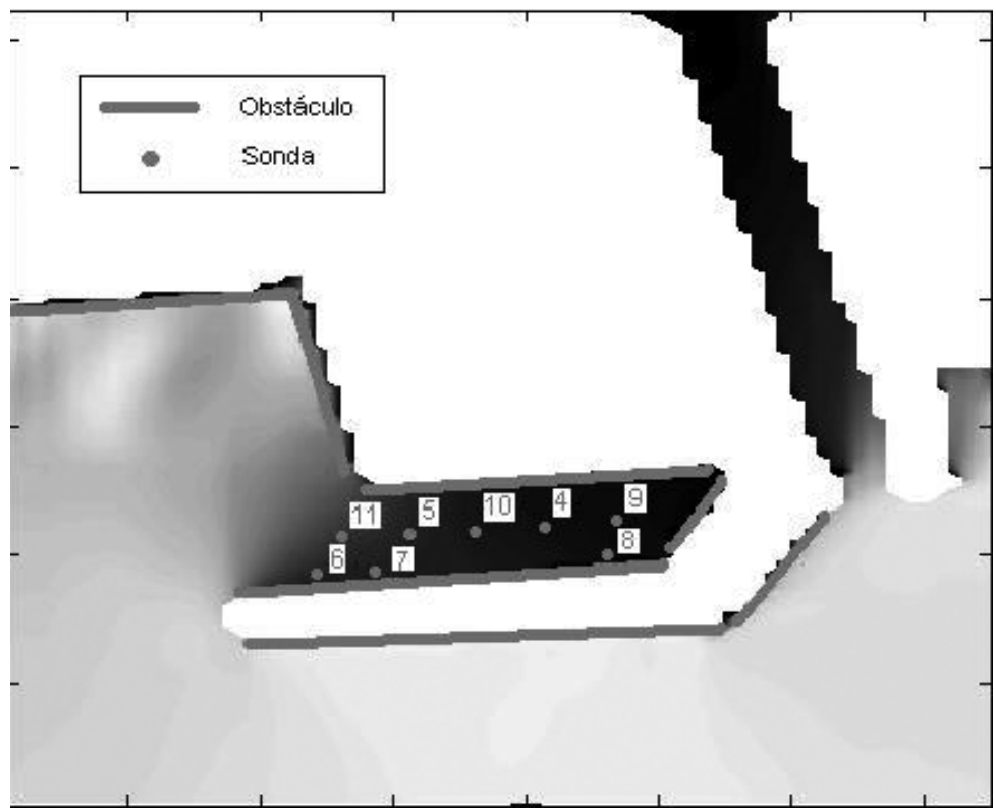

Figura 5 - Linhas de obstáculo representadas pelos tons de cinza mais escuro no entorno do Terminal Portuário da CST, onde a reflexão é computada no SWAN. Também estão representadas as posições das sondas do modelo reduzido, pontos onde foram estimados os valores de altura significativa no SWAN e no MIKE21 BW.

reflexão para todos os locais definidos como sendo terra, e caso se deseje desligar a reflexão, esses lugares são estipulados a priori. Para tanto são definidas regiões, incluindo os limites do domínio computacional, onde o modelo interpreta como sendo uma camada esponja que absorve toda a energia das ondas que chega a este local, não permitindo que ocorra reflexão.

No SWAN, para reduzir o esforço computacional, optou-se por utilizar um grid mais grosseiro com espaçamento de $40 \mathrm{~m}$, diminuindo a matriz para 131 por 205 pontos. Na área mais próxima ao porto foi empregado um aninhamento utilizando o grid de $8 \mathrm{~m}$, por estarem aí localizados os pontos de medição empregados na comparação. Esta área é apresentada na Figura 5, com a posição relativa das sondas.

O SWAN, ao contrário do MIKE 21 BW, não computa a reflexão em todos os locais onde há terra. Neste modelo é necessário que se informe o coeficiente de reflexão a ser utilizado, e que seja definido um segmento onde a reflexão deve ser calculada, fornecendo as coordenadas das suas extremidades. Esse segmento pode ser pensado como uma linha de obstáculo, no qual a energia das ondas é refletida. Foram escolhidos 7 segmentos ao redor do porto onde a reflexão é importante, com suas posições apresentadas na Figura 5.

Além da possibilidade de habilitar ou não a difração, o SWAN possui alguns parâmetros programáveis pelo usuário para con- trolar a maneira como a difração é computada. Os parâmetros SMPAR e SMNUM, basicamente, são empregados para controlar a quantidade de alisamento entre pontos de grid adjacentes, reduzindo diferenças muito abruptas e aumentando a estabilidade numérica. Várias combinações de valores foram testadas, sem diferenças significativas nos resultados obtidos, mantendose então os valores sugeridos no manual de operação (SWAN Team, 2006).

\section{RESULTADOS E DISCUSSÕES}

Através das simulações feitas no modelo físico reduzido foram obtidas as alturas significativas nas 8 sondas utilizadas, cujos valores estão apresentados na Tabela 2. Pode-se observar que as ondas de maior altura ao largo apresentam maiores valores dentro do porto, e como esses valores decrescem à medida que consideramos posições cada vez mais abrigadas. Essas medições são empregadas como os valores de referência para a avaliação do desempenho dos modelos numéricos.

Na Tabela 3 estão listados os valores de altura significativa estimados pelo MIKE 21 BW para as posições representativas das sondas. Observa-se um decaimento gradual a partir da entrada do porto até a região mais abrigada, na maior parte das medições, com exceção de dois valores aparentemente anômalos na linha 2. 0 primeiro, na simulação da onda de 1,5 m, onde 
a sonda 7 apresenta um acréscimo de $1 \mathrm{~cm}$ em relação à sonda 6 . 0 segundo valor que foge ao padrão ocorre na simulação da onda de $2,5 \mathrm{~m}$, onde a sonda 6 apresenta um valor muito superior à sonda 7 , gerando um decaimento mais abrupto do que nas outras três simulações.

Tabela 2 - Valores de altura significativa $\left(H_{S}\right)$ obtidos pelas sondas no modelo físico reduzido, convertidos para os valores que seriam observados no porto em escala real, ao longo das duas linhas de medição (Fig. 5). As quatro simulações estão apresentadas, ou seja, para alturas de 1,0, 1,5, 2,0 e 2,5 m ao largo (os 4 espectros apresentados na Fig. 3). As posições das sondas empregadas no modelo reduzido são apresentadas na Figura 5, onde as distância entre elas também estão listadas, com valores correspondentes ao seu valor real dentro do porto. A sonda mais externa (na posição menos abrigada) é tomada como referência (posição 0 m).

\begin{tabular}{|c|c|c|c|c|c|}
\hline \multicolumn{6}{|c|}{ Modelo Físico } \\
\hline \multicolumn{2}{|c|}{ Sonda } & \multicolumn{5}{|c|}{ Hs (m) } \\
\hline$n^{\circ}$ & $\begin{array}{c}\text { Posição } \\
(\mathrm{m})\end{array}$ & 1,00 & 1,50 & 2,00 & 2,50 \\
\hline \multicolumn{6}{|c|}{ Linha 1} \\
\hline $\mathbf{1 1}$ & $\mathbf{0}$ & 0,24 & 0,31 & 0,41 & 0,62 \\
\hline $\mathbf{5}$ & $\mathbf{5 0}$ & 0,19 & 0,24 & 0,30 & 0,39 \\
\hline $\mathbf{1 0}$ & $\mathbf{9 0}$ & 0,18 & 0,23 & 0,28 & 0,35 \\
\hline $\mathbf{4}$ & $\mathbf{1 3 0}$ & 0,16 & 0,20 & 0,22 & 0,30 \\
\hline $\mathbf{9}$ & $\mathbf{1 7 0}$ & 0,14 & 0,19 & 0,20 & 0,31 \\
\hline \multicolumn{6}{|c|}{ Linha 2 } \\
\hline $\mathbf{6}$ & $\mathbf{0}$ & 0,28 & 0,33 & 0,43 & 0,57 \\
\hline $\mathbf{7}$ & $\mathbf{3 0}$ & 0,17 & 0,26 & 0,33 & 0,41 \\
\hline $\mathbf{8}$ & $\mathbf{1 9 0}$ & 0,16 & 0,21 & 0,22 & 0,33 \\
\hline
\end{tabular}

Tabela 3 - Valores de altura significativa $\left(H_{S}\right)$ estimados pelo MIKE $21 \mathrm{BW}$ nas posições correspondentes às sondas no modelo físico reduzido.

\begin{tabular}{|c|c|c|c|c|c|}
\hline \multicolumn{6}{|c|}{ MIKE 21 } \\
\hline \multicolumn{7}{|c|}{ Sonda } & \multicolumn{5}{c|}{ Hs (m) } \\
\hline$n^{\circ}$ & $\begin{array}{c}\text { Posição } \\
(\mathrm{m})\end{array}$ & 1,00 & 1,50 & 2,00 & 2,50 \\
\hline \multicolumn{6}{|c|}{ Linha 1 } \\
\hline $\mathbf{1 1}$ & $\mathbf{0}$ & 0,23 & 0,34 & 0,38 & 0,64 \\
\hline $\mathbf{5}$ & $\mathbf{5 0}$ & 0,16 & 0,22 & 0,27 & 0,45 \\
\hline $\mathbf{1 0}$ & $\mathbf{9 0}$ & 0,13 & 0,16 & 0,20 & 0,33 \\
\hline $\mathbf{4}$ & $\mathbf{1 3 0}$ & 0,11 & 0,16 & 0,17 & 0,29 \\
\hline $\mathbf{9}$ & $\mathbf{1 7 0}$ & 0,10 & 0,12 & 0,16 & 0,29 \\
\hline \multicolumn{7}{|c|}{ Linha 2 } \\
\hline $\mathbf{6}$ & $\mathbf{0}$ & 0,17 & 0,23 & 0,32 & 0,60 \\
\hline $\mathbf{7}$ & $\mathbf{3 0}$ & 0,17 & 0,24 & 0,31 & 0,48 \\
\hline $\mathbf{8}$ & $\mathbf{1 9 0}$ & 0,10 & 0,13 & 0,14 & 0,24 \\
\hline
\end{tabular}

As simulações empregando o SWAN foram realizadas, em um primeiro momento, com a difração ligada e com a reflexão desligada (sem a presença das linhas de obstáculo). Neste caso o modelo funcionou normalmente, convergindo em aproximadamente dez iterações. Um segundo teste foi feito, agora com a difração desligada e com a reflexão ligada (linhas de obstáculo presentes). 0 modelo também funcionou perfeitamente, convergindo em torno de cinco iterações. Porém, ao se ligar a difração e a reflexão simultaneamente, 0 modelo não convergiu. Nesta configuração, o modelo atingia uma acurácia superior a 80\% nas primeiras duas ou três iterações, caindo abruptamente em seguida, e permanecendo com valores inferiores a $2 \%$.

Os valores de altura significativa foram extraídos nas iterações em que o modelo alcançou a maior acurácia durante o processamento, mesmo não ocorrendo convergência posterior. Para cada simulação empregando as quatro diferentes alturas de onda ao largo, estes valores foram comparados com os obtidos na iteração imediatamente posterior, quando a acurácia começava a decrescer (mínimo de 14\%). Verificou-se que, na maioria dos casos, a diferença máxima entre os valores obtidos para os pontos das sondas nas diferentes iterações eram inferiores a $1 \mathrm{~cm}$. Desta forma, decidiu-se empregar nas comparações os valores de altura significativa obtidos na iteração de maior valor de acurácia encontrada com a difração e a reflexão ligadas, mesmo que posteriormente não ocorresse convergência. Adicionalmente, foram empregados os valores de altura significativa encontrados nas simulações com a difração desligada e a reflexão ligada. Com os resultados destes dois casos tornou-se possível investigar se o efeito da difração estar habilitada ou não é realmente importante para as simulações no porto.

Nas Tabelas 4 e 5 estão listados os valores de altura significativa extraídos das posições representativas das sondas, computados com o SWAN com a difração desligada e com a difração ligada, respectivamente (em ambas a opção de reflexão estava habilitada). Todos os pontos apresentaram valores coerentes, com decaimento de energia nas posições mais abrigadas. Apenas 0 valor de altura significativa na sonda 7 , na simulação da onda de 2,5 $\mathrm{m}$ ao largo com a difração desligada, apresentou um valor aparentemente anômalo, por ser maior do que o obtido na sonda 6 , que é menos abrigada.

Os gráficos com os resultados obtidos pelo modelo reduzido, pelo MIKE 21 BW e pelo SWAN com a difração desligada e com a difração ligada são apresentados nas Figuras 6, 7, 8 e 9, respectivamente, para as simulações com alturas de onda ao largo de 1,0, 1,5, 2,0 e 2,5 m.

Observando os gráficos relativos à linha 1 (Figs. 6a, 7a, 8a e 9a), pode-se notar que os modelos apresentam comportamento semelhante, independente das alturas de onda ao largo. De forma 
geral o modelo MIKE $21 \mathrm{BW}$ tende a subestimar os valores medidos pelas sondas porém, comparativamente, os valores estimados por este modelo são sempre mais próximos das medições. 0 SWAN, por outro lado, apresenta um comportamento menos constante, geralmente subestimando as medições na parte abrigada do porto, enquanto que na parte mais exposta (representada pela posição 0 no eixo horizontal) os valores são superestimados. Também é possível destacar que os valores computados de altura significativa no SWAN com a difração ligada são maiores do que os com a difração desligada. No ponto mais exposto (sonda 11) a estimativa do SWAN com a difração desligada é mais próxima do resultado do modelo físico do que com a difração ligada.

Tabela 4 - Valores de altura significativa $\left(H_{S}\right)$ estimados pelo SWAN nas posições correspondentes às sondas no modelo físico reduzido, para a opção de difração desligada e reflexão ligada.

\begin{tabular}{|c|c|c|c|c|c|}
\hline \multicolumn{6}{|c|}{ SWAN dif off } \\
\hline \multicolumn{2}{|c|}{ Sonda } & \multicolumn{5}{c|}{ Hs (m) } \\
\hline$n^{\circ}$ & $\begin{array}{c}\text { Posição } \\
(\mathrm{m})\end{array}$ & 1,00 & 1,50 & 2,00 & 2,50 \\
\hline \multicolumn{6}{|c|}{ Linha 1} \\
\hline $\mathbf{1 1}$ & $\mathbf{0}$ & 0,23 & 0,38 & 0,47 & 0,51 \\
\hline $\mathbf{5}$ & $\mathbf{5 0}$ & 0,21 & 0,30 & 0,39 & 0,48 \\
\hline $\mathbf{1 0}$ & $\mathbf{9 0}$ & 0,12 & 0,17 & 0,22 & 0,26 \\
\hline $\mathbf{4}$ & $\mathbf{1 3 0}$ & 0,07 & 0,11 & 0,13 & 0,16 \\
\hline $\mathbf{9}$ & $\mathbf{1 7 0}$ & 0,04 & 0,07 & 0,08 & 0,09 \\
\hline \multicolumn{7}{|c|}{ Linha 2 } \\
\hline $\mathbf{6}$ & $\mathbf{0}$ & 0,17 & 0,24 & 0,30 & 0,37 \\
\hline $\mathbf{7}$ & $\mathbf{3 0}$ & 0,16 & 0,23 & 0,30 & 0,39 \\
\hline $\mathbf{8}$ & $\mathbf{1 9 0}$ & 0,06 & 0,10 & 0,12 & 0,14 \\
\hline
\end{tabular}

Tabela 5 - Valores de altura significativa $\left(H_{S}\right)$ estimados pelo SWAN nas posições correspondentes às sondas no modelo físico reduzido, para a opção de difração ligada e reflexão ligada.

\begin{tabular}{|c|c|c|c|c|c|}
\hline \multicolumn{6}{|c|}{ SWAN dif on } \\
\hline \multicolumn{2}{|c|}{ Sonda } & \multicolumn{5}{|c|}{ Hs (m) } \\
\hline$n^{\circ}$ & $\begin{array}{c}\text { Posição } \\
(\mathrm{m})\end{array}$ & 1,00 & 1,50 & 2,00 & 2,50 \\
\hline \multicolumn{6}{|c|}{ Linha 1 } \\
\hline $\mathbf{1 1}$ & $\mathbf{0}$ & 0,30 & 0,45 & 0,59 & 0,74 \\
\hline $\mathbf{5}$ & $\mathbf{5 0}$ & 0,19 & 0,29 & 0,37 & 0,48 \\
\hline $\mathbf{1 0}$ & $\mathbf{9 0}$ & 0,12 & 0,19 & 0,25 & 0,33 \\
\hline $\mathbf{4}$ & $\mathbf{1 3 0}$ & 0,08 & 0,13 & 0,16 & 0,22 \\
\hline $\mathbf{9}$ & $\mathbf{1 7 0}$ & 0,06 & 0,10 & 0,11 & 0,15 \\
\hline \multicolumn{7}{|c|}{ Linha 2 } \\
\hline $\mathbf{6}$ & $\mathbf{0}$ & 0,21 & 0,30 & 0,39 & 0,43 \\
\hline $\mathbf{7}$ & $\mathbf{3 0}$ & 0,19 & 0,27 & 0,36 & 0,38 \\
\hline $\mathbf{8}$ & $\mathbf{1 9 0}$ & 0,07 & 0,11 & 0,14 & 0,19 \\
\hline
\end{tabular}

Comparação semelhante pode ser conduzida em relação à linha 2 (Figs. 6b, 7b, 8b e 9b). As estimativas do MIKE 21 BW aparentam ser ligeiramente mais próximas das medições do que as estimativas do SWAN, embora não tão claramente quanto na linha 1. Ambos os modelos de forma geral subestimaram as medições das sondas, com exceção do MIKE 21 BW que superestimou os pontos menos abrigados no caso de ondas ao largo de 2,5 $\mathrm{m}$ (Fig. 9b). Da mesma forma como na linha 1, os valores do SWAN com a difração ligada são sempre maiores do que com a difração desligada, além de serem mais próximos dos valores medidos. Contudo a diferença entre as estimativas do modelo com a difração ligada e desligada nos pontos mais abrigados (sondas 4 e 9 na linha 1 e 8 na linha 2) é sempre pequena, com máximo valor computado de $6 \mathrm{~cm}$.

Coeficientes de correlação foram obtidos entre as medições e o MIKE 21 BW, o SWAN com a difração ligada e o SWAN com a difração desligada. Para aumentar a significância estatística, foram computados todos os valores ao longo das linhas 1 e 2 para as quatro condições de altura de onda ao largo, perfazendo 32 pontos. Como a inspeção visual dos gráficos indica, a maior correlação com as medições foi obtida pelo MIKE 21 BW, com coeficiente de 95\% (desvio padrão de $13 \mathrm{~cm}$ ). A correlação com 0 SWAN é ligeiramente inferior, com 86\% e 80\% respectivamente para a condição de difração ligada e difração desligada (desvio padrão de $13 \mathrm{~cm}$ e $12 \mathrm{~cm}$ ). Para efeito de comparação, o coeficiente de correlação entre o SWAN com a difração ligada e o SWAN com a difração desligada é de $96 \%$ e o desvio padrão de $13 \mathrm{~cm}$.

Testes adicionais foram realizados desligando-se a opção de reflexão enquanto que a difração permanecia ligada no SWAN, onde os valores de altura significativa estimados nesta situação são muito inferiores às medições, especialmente ao longo da linha 2. A direção de propagação, juntamente com os valores de altura significativa para a onda de 1,0 m ao largo, é apresentada na Figura 10. Na Figura 11 são mostrados os resultados ao longo das linhas 1 e 2, além das estimativas apresentadas anteriormente (do MIKE 21 BW, do SWAN com a difração ligada e desligada quando a reflexão está habilitada, além das medições). Na sonda 8, que é a mais interna da linha 2, o valor de altura significativa chega a zero. Resultados semelhantes foram obtidos empregando os quatro espectros, sendo aqui apresentado somente os resultados relativos ao de altura de $1,0 \mathrm{~m}$ ao largo.

A reflexão contribui mais significativamente do que difração para a presença de ondas dentro do porto, uma vez que os vaIores com a difração desligada e a reflexão ligada se aproximam mais das medições e das estimativas do MIKE 21 BW do que os resultados com a reflexão desligada e a difração ligada. A média 


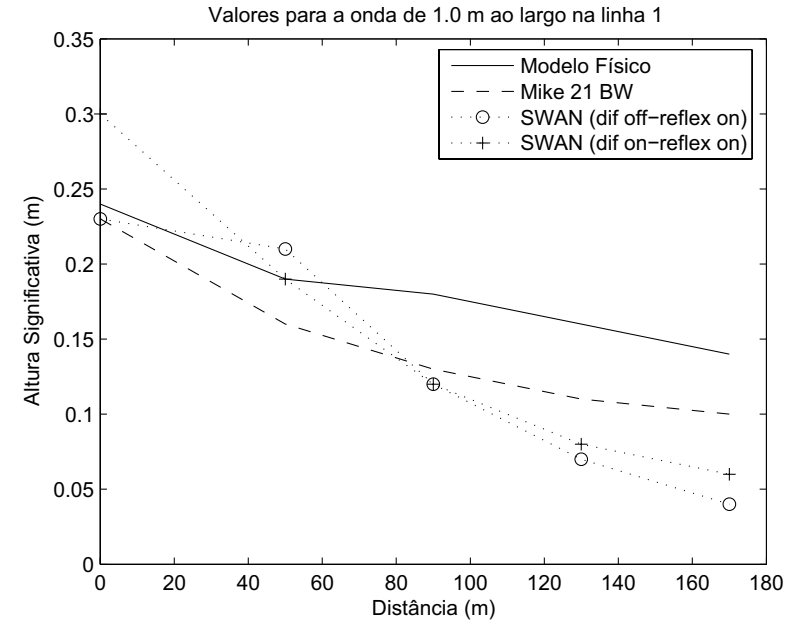

(a)

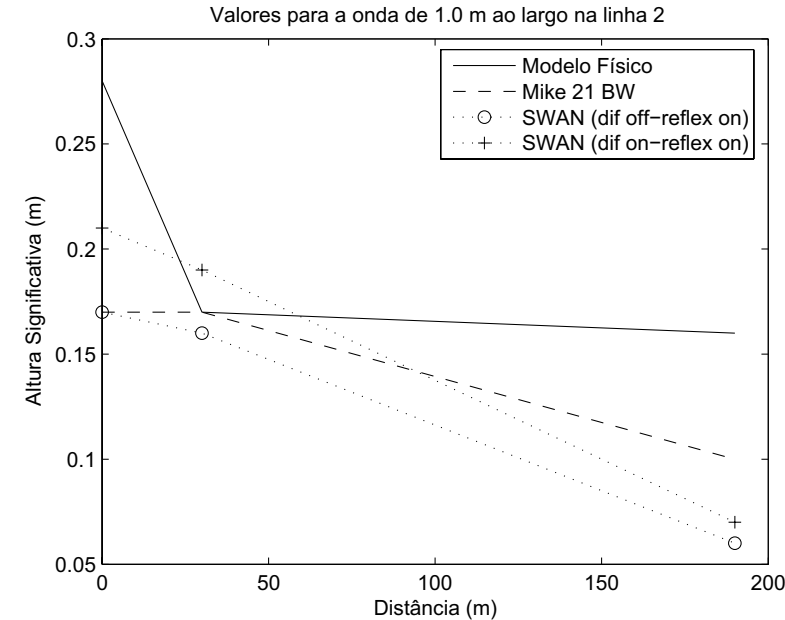

(b)

Figura 6 - Valores de altura significativa obtidos através do modelo físico reduzido, do MIKE 21 BW e do SWAN com a reflexão ligada para: a difração desligada (dif off-reflex on) e a difração ligada (dif on—reflex on). Para a onda de 1,0 m ao largo, (a) na linha 1 e (b) na linha 2.

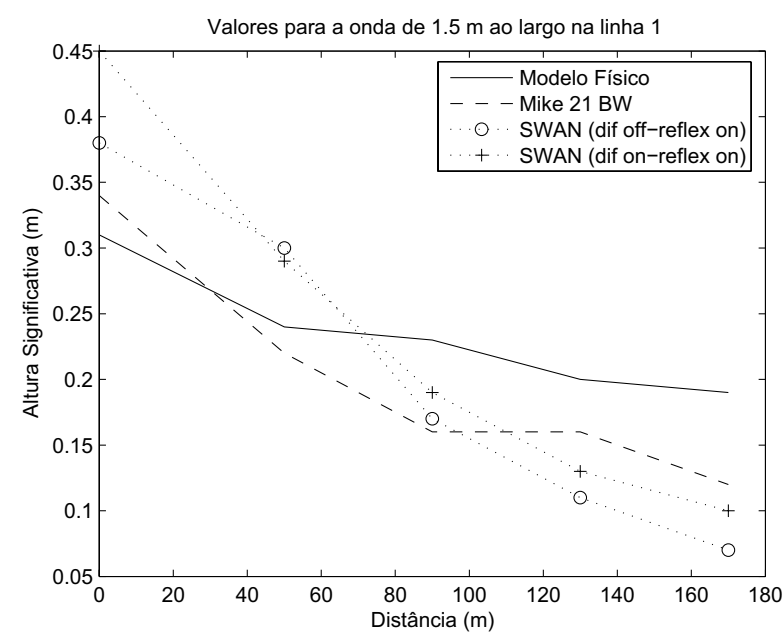

(a)

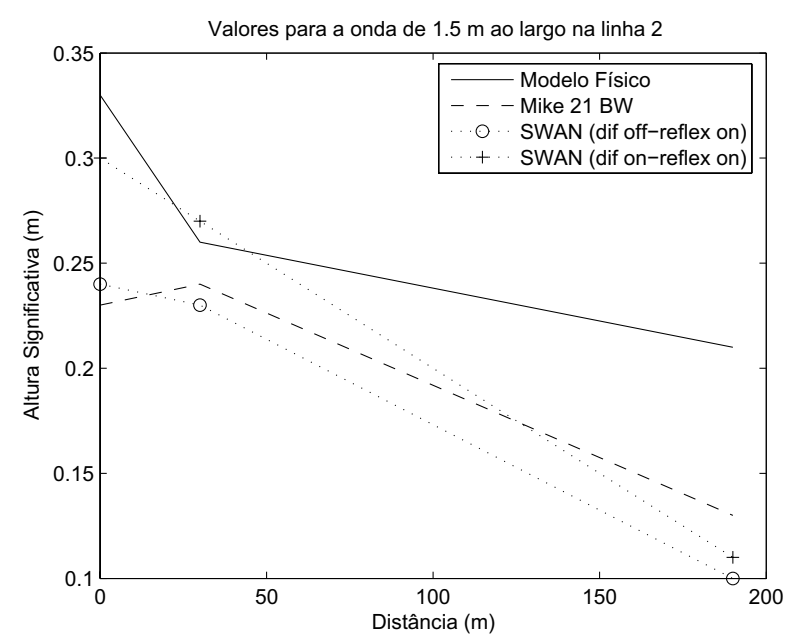

(b)

Figura 7 - Valores de altura significativa obtidos através do modelo físico reduzido, do MIKE 21 BW e do SWAN com a reflexão ligada para: a difração desligada (dif off—reflex on) e a difração ligada (dif on—reflex on). Para a onda de 1,5 m ao largo, (a) na linha 1 e (b) na linha 2.

das diferenças entre as estimativas do SWAN—para a opção de difração desligada e reflexão ligada—e do modelo físico, são de 6, 8, 9 e $13 \mathrm{~cm}$, respectivamente, para as ondas de 1, 1,5, 2 e 2,5 $\mathrm{m}$ ao largo. Esses valores correspondem a 6, 5,3, 4,5 e 5,2\% da altura significativa das ondas ao largo.

\section{CONCLUSÕES}

Informações confiáveis sobre a maneira como ondas se propagam a sotamar de quebra-mares são importantes para o projeto de por- tos. Tais informações são obtidas, geralmente, através de modelos numéricos computacionais ou através de modelos físicos reduzidos, onde uma determinada região é representada em escala no laboratório. No presente estudo, as duas opções foram empregadas para simular ondas irregulares em um terminal portuário, proporcionando uma excelente oportunidade para a investigação de efeitos relativamente complexos como difração e reflexão de ondas.

0 modelo de terceira geração SWAN, um programa freeware disponível na web e de grande aceitação pela comunidade cien- 


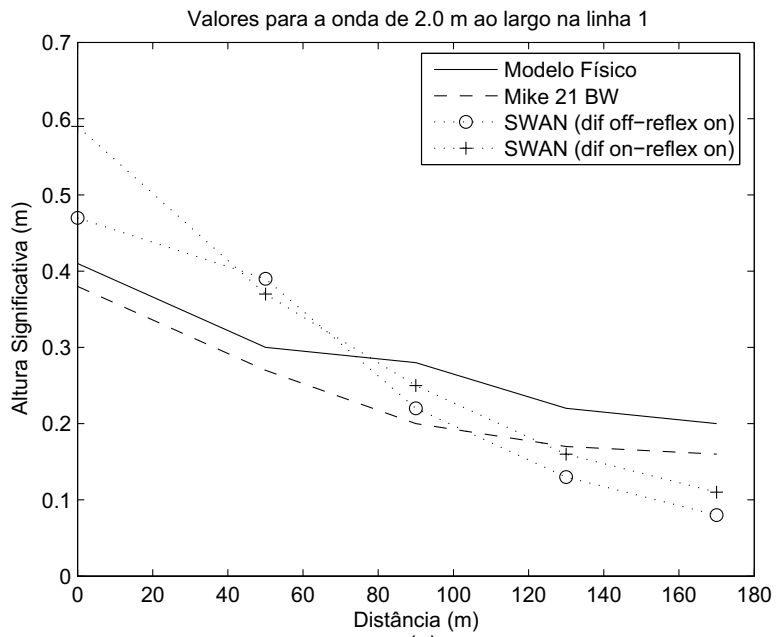

(a)

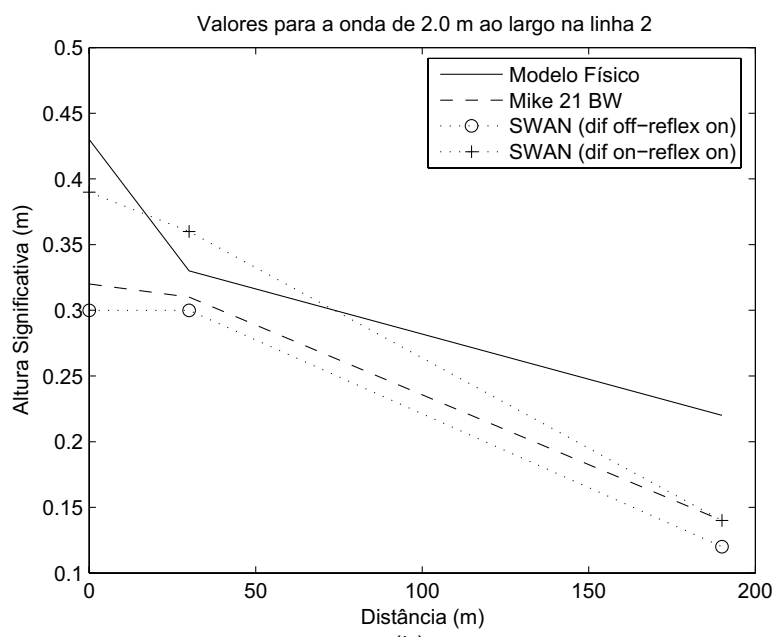

(b)

Figura 8 - Valores de altura significativa obtidos através do modelo físico reduzido, do MIKE 21 BW e do SWAN com a reflexão ligada para: a difração desligada (dif off-reflex on) e a difração ligada (dif on—reflex on). Para a onda de 2,0 m ao largo, (a) na linha 1 e (b) na linha 2.

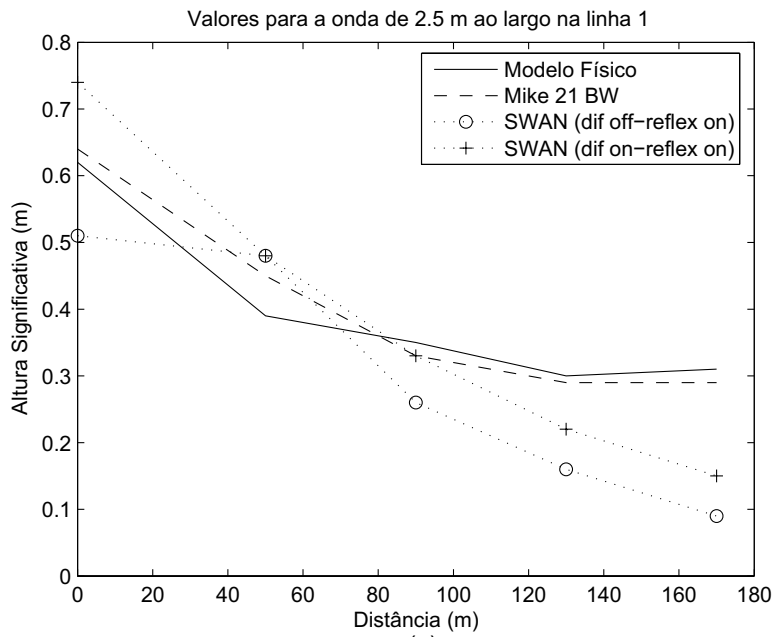

(a)

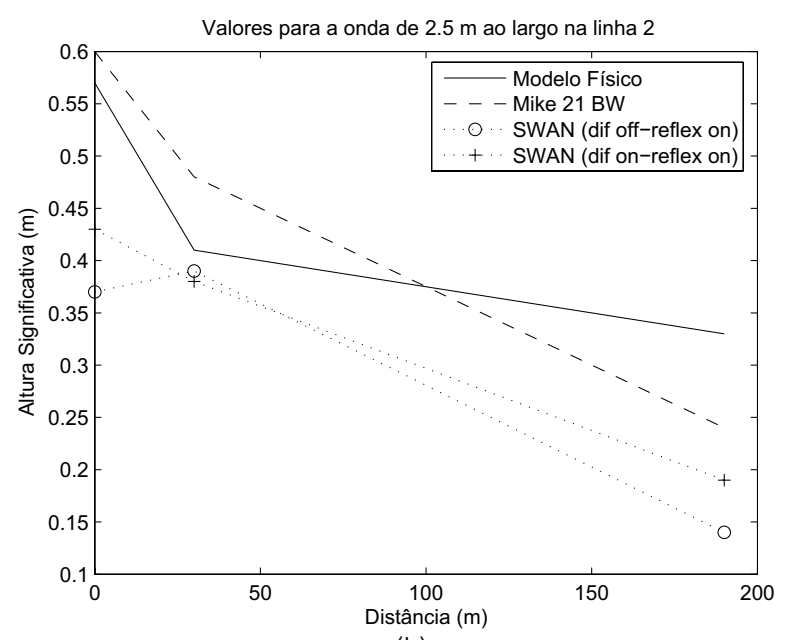

(b)

Figura 9 - Valores de altura significativa obtidos através do modelo físico reduzido, do MIKE 21 BW e do SWAN com a reflexão ligada para: a difração desligada (dif off-reflex on) e a difração ligada (dif on—reflex on). Para a onda de 2,5 m ao largo, (a) na linha 1 e (b) na linha 2.

tífica, lançou recentemente a opção de se computar a difração. 0 efeito da difração é normalmente calculado em modelos que resolvem a fase da onda, como o MIKE 21 BW. Em contrapartida, modelos espectrais como o SWAN não computam a fase das ondas calculando valores médios, onde a implementação do cálculo da difração é menos simples devido às equações governantes empregadas (SWAN Team, 2006). Desta forma, a possibilidade de se comparar o desempenho do SWAN e do MIKE 21 BW com medições realizadas em uma região onde a reflexão e difração são importantes se apresenta como uma grande oportunidade de avaliação de dois modelos bastante diferentes em termos de concepção, custos e velocidade de processamento. Porém, o presente trabalho foca mais particularmente no SWAN e a viabilidade do seu recém lançado módulo de cálculo da difração.

De forma geral existe um certo questionamento na importância de se calcular a difração quando as ondas apresentam relativamente um maior espalhamento direcional, caracterizadas por cristas curtas. Em tal situação, a sotamar de um obstáculo, devido ao número relativamente grande de direções de propagação que estão ocorrendo simultaneamente, 0 efeito de redução de energia 


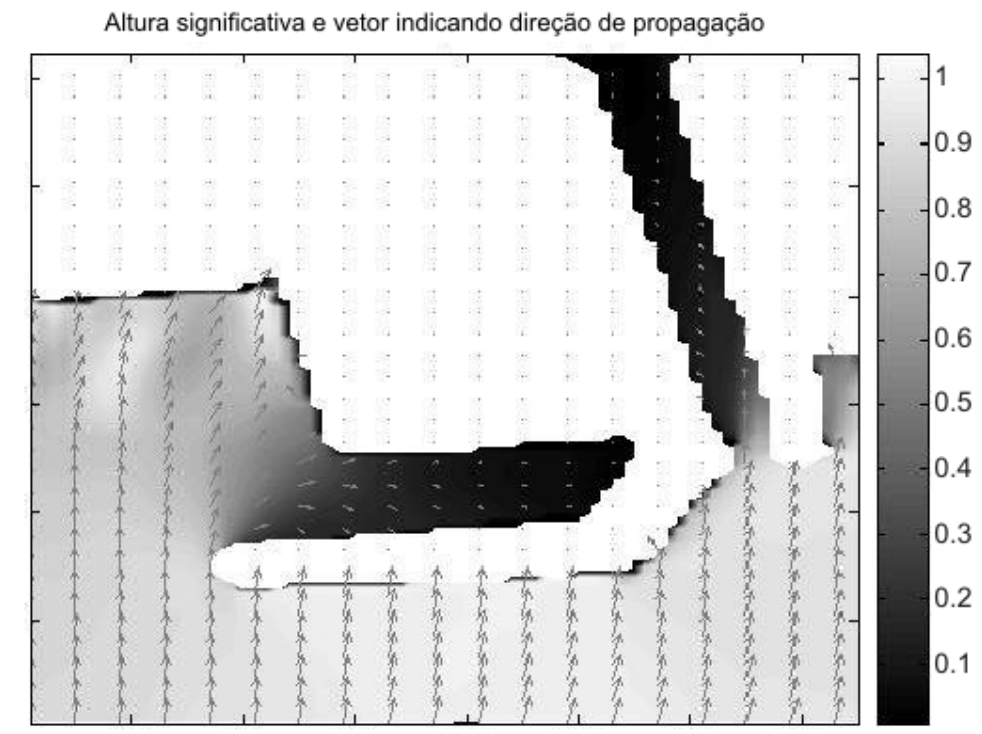

Figura 10 - Tons de cinza representando a variação da altura significativa dentro do terminal portuário estimada pelo SWAN com a opção de reflexão desligada enquanto que a difração permanece ligada. A direção de propagação é representada pelas setas. 0 espectro com altura significativa de 1,0 $\mathrm{m}$ ao largo é empregado.

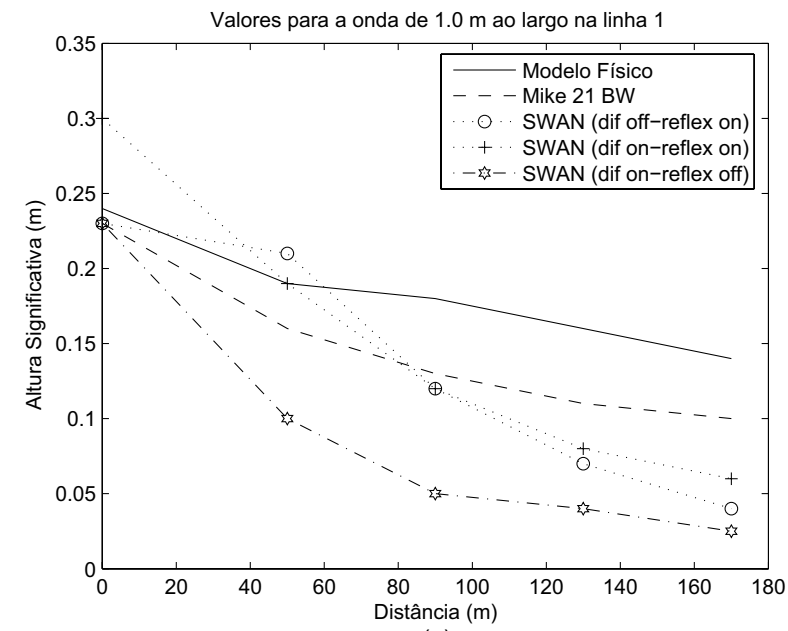

(a)

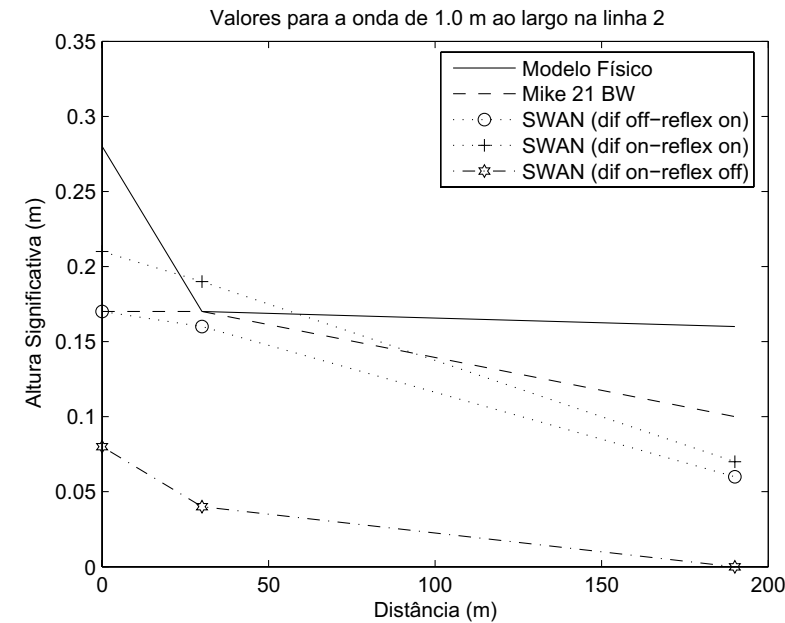

(b)

Figura 11 - Valores de altura significativa obtidos através do modelo físico reduzido, do MIKE 21 BW e do SWAN com a reflexão ligada para: a difração desligada (dif off-reflex on) e a difração ligada (dif on—reflex on). Também estão representados os valores com a reflexão desligada e a difração ligada (dif on—reflex off), para a onda de 1,0 $\mathrm{m}$ ao largo, (a) na linha $1 \mathrm{e}$ (b) na linha 2.

das ondas é muito menos significativo. De forma contrária, ondas regulares, com cristas longas e espalhamento direcional relativamente mais estreito, apresentam uma redução considerável de energia à sotamar de um obstáculo, quando comparado com ondas irregulares. A menor importância da difração no caso de ondas irregulares, como as apresentadas no terminal da CST, fica evidente quando são comparados os resultados com a difração ligada e desligada, cujos valores computados pelo SWAN apresentam pouca diferença. Porém a opção com a difração ligada gera resultados mais condizentes com as medições, representando um ganho nas estimativas do SWAN em tais situações.

Ao contrário da difração, a reflexão de ondas irregulares pode ser de extrema importância dentro de um porto, como constatado pelas simulações com a difração habilitada e a reflexão não. 
Em tal cenário, os valores computados pelo SWAN foram muito inferiores aos valores observados, indicando sua grande significância. Em algumas simulações, o simples efeito de se desconsiderar a reflexão implicou em valores de altura significativa de onda igual a zero nas regiões mais abrigadas. Obstáculos dentro de um porto, como um muro de concreto, podem refletir a totalidade da energia incidente, possibilitando a criação de ondas estacionárias. Não seria possível nesse caso computar essas ondas empregando um modelo espectral, devido a necessidade de se determinar a fase das ondas incidentes.

Com as configurações aqui empregadas, o SWAN apresentou convergência nos resultados quando a difração e a reflexão foram habilitadas separadamente. Entretanto, 0 uso simultâneo das duas opç̃oes é claramente observado como um ponto crítico na utilização deste modelo para áreas portuárias. A instabilidade observada ao se utilizar a reflexão e a difração ao mesmo tempo, com o modelo não apresentando convergência em seus resultados, pode ser explicada pela possível formação de ondas estacionárias dentro do porto. Holthuijsen (2007) alerta para o fato de que a opção de difração no SWAN não deve ser habilitada nas proximidades de obstáculos que causam reflexão das ondas incidentes. Nesta situação, a formação de ondas estacionárias requer a informação da fase das ondas, não disponível em modelos espectrais como o SWAN. Possivelmente a não solução destas ondas causa a diferença de valores computados entre iterações sucessivas, causando a não convergência dos resultados.

No presente trabalho, as estimativas do SWAN empregando a recém lançada opção de cálculo da difração foram comparadas com simulações realizadas em um modelo físico reduzido e com um modelo numérico que resolve a fase das ondas. A área onde as medições foram realizadas se localiza dentro de um porto, onde efeitos de difração e reflexão são relevantes. Foi demonstrada a menor importância da difração para ondas irregulares, com espalhamentos direcionais largos, dentro da área abrigada do porto. Embora a opção de habilitar a difração tenha implicado numa maior correlação das estimativas do modelo com as mediç̃es, o SWAN não apresentou convergência dos resultados, caracterizando uma limitação do modelo. Portanto em situações tipicamente encontradas em portos, com ondas irregulares com cristas curtas, a atual versão do SWAN deve ser empregada com a difração desligada e a reflexão ligada. Naturalmente, modelos que resolvem a fase da onda são mais indicados em tais situações, porém a diferença média entre as estimativas do SWAN com a difração desligada (e a reflexão ligada) e o modelo físico é de somente $5 \%$ dos valores da altura da onda significativa ao largo.

\section{AGRADECIMENTOS}

Ao Instituto de Pesquisas Hidroviárias pela cessão dos dados do modelo reduzido e da batimetria. Os autores também gostariam de expressar seus agradecimentos a Victor Amorim D'Ávila e Rogério Candella pelas sugestões e comentários a uma versão preliminar deste artigo.

\section{REFERÊNCIAS}

BOOIJ N, RIS R \& HOLTHUIJSEN L. 1999. A third-generation wave model for coastal regions: 1. model description and validation. J Geophys Res, 104(C4): 7649-7666.

DHI. 1998. MIKE 21 - User guide and reference manual, release 2.7. Technical report, Danish Hydraulic Institute. Denmark, 98 p.

ENET F, NAHON A, VAN VLEDDER G \& HURDLE D. 2006. Evaluation of diffraction behind a semi-infinite breakwater in the SWAN Wave Model. In: Proceedings of Ninth International Symposium on Ocean Wave Measurement and Analysis - WAVESO6. CD-ROM.

HANSEN KH, KERPER DR, SORENSEN OR \& KIRKEGAARD DJ. 2005. Simulation of long wave agitation in ports and harbours using a timedomain Boussinesq model. In: Proceedings of Fitth International Symposium on Ocean Wave Measurement and Analysis - WAVES 2005. Madrid, Spain. CD-ROM.

HOLTHUIJSEN LH. 2007. Waves in Oceanic and Coastal Waters. Cambridge University Press, Great Britain. 387 p.

HOLTHUIJSEN LH, HERMAN A \& BOOIJ N. 2003. Phase-decoupled refraction-diffraction for spectral wave models. Coastal Engineering, 49: 291-305

INPH. 2003a. A evolução dos sistemas de geração de ondas do INPH. Instituto de Pesquisas Hidroviárias. Relatório Técnico. $52 \mathrm{p}$.

INPH. 2003b. Modelagem matemática de propagaçãa das ondas no terminal de barcaças oceânicas da CST. Instituto de Pesquisas Hidroviárias. Relatório Técnico. 70 p.

MADSEN P, MURRAY I \& SORENSEN 0. 1991. A new form of the Boussinesq equations with improved linear dispersion characteristics. Coastal Engineering, 15: 371-388.

MADSEN P \& SORENSEN 0. 1992. A new form of the Boussinesq equations with improved linear dispersion characteristics. Part 2: A slowlyvarying bathymetry. Coastal Engineering, 18: 183-204.

MEIRELLES S \& VIOLANTE-CARVALHO N. 2007. Modelagem computacional da propagação de ondas superficiais no oceano: um subsídio para a compreensão dos fenômenos ópticos. Revista Brasileira de Ensino de Física, 29: 555-563.

SORENSEN OR, SCHAFFER HA \& SORENSEN LS. 2004. Boussinesqtype modelling using an unstructured finite element technique. Coastal Engineering, 50: 181-198. 
SWAN TEAM. 2006. SWAN User Manual version 40.51. Department of Civil Engineering and Geosciences, Delft University of Technology, Delft, The Netherlands. $111 \mathrm{p}$.

TOLMAN H. 1991. A third-generation model for wind waves on slowly varying, unsteady and inhomogeneous depths and currents. Journal of Physical Oceanography, 21: 782-797.

TUCKER MJ \& PITT EG. 2001. Waves in ocean engineering. Elsevier ocean engineering book series, vol. 5. Elsevier, Amsterdam, $521 \mathrm{p}$.
VIOLANTE-CARVALHO N, OCAMPO-TORRES FJ \& ROBINSON IS. 2004. Buoy observations of the influence of swell on wind waves in the open ocean. Applied Ocean Research, 26(1-2): 49-60.

WAMDI GROUP. 1988. The WAM model - A third generation ocean wave prediction model. Journal of Physical Oceanography, 18: 1775-1810.

ZIJLEMA M \& VAN DER WESTHUYSEN AJ. 2005. On convergence behaviour and numerical accuracy in stationary SWAN simulations of nearshore wind wave spectra. Coastal Engineering, 52(3): 237-256.

\section{NOTAS SOBRE OS AUTORES}

Rafael B. Paes-Leme é oceanógrafo formado na Universidade do Estado do Rio de Janeiro (UERJ), trabalhando atualmente na empresa SubSea 7.

Nelson Violante-Carvalho é oceanógrafo formado na UERJ, com mestrado em engenharia oceânica na COPPE/UFRJ e doutorado em oceanografia física pela Universidade de Southampton, Inglaterra. Atualmente é professor visitante da UERJ.

Domenico Accetta é engenheiro, atuando como Superintendente do INPH.

Saulo Meirelles é oceanógrafo formado na UERJ. 